\title{
Prognostic significance of the red blood cell distribution width in diffuse large B-cell lymphoma patients
}

\author{
Shujuan Zhou ${ }^{1}$, Fang Fang ${ }^{1}$, Huiyao Chen ${ }^{1}$, Wei Zhang ${ }^{1}$, Yang Chen ${ }^{1}$, Yifen Shi ${ }^{1}$, \\ Zhouyi Zheng ${ }^{2}$, Yongyong Ma ${ }^{1}$, Liyuan Tang ${ }^{1}$, Jianhua Feng ${ }^{1}$, Yu Zhang ${ }^{1}$, Lan Sun ${ }^{1}$, \\ Yi Chen ${ }^{1}$, Bin Liang ${ }^{1}$, Kang $\mathbf{Y u}^{1}$ and Songfu Jiang ${ }^{1}$ \\ ${ }^{1}$ Department of Hematology, The First Affiliated Hospital of Wenzhou Medical University, Wenzhou, Zhejiang, P.R. China \\ ${ }^{2}$ Department of Hematology and Oncology, Traditional Chinese Medical Hospital of Zhuji, Shaoxing, Zhejiang, P.R. China \\ Correspondence to: Songfu Jiang, email: 20442947@qq.com \\ Kang Yu, email: yukang@163.com \\ Keywords: diffuse large B cell lymphoma, red blood cell distribution width, prognosis, survival \\ Received: November 30, $2016 \quad$ Accepted: March 09, $2017 \quad$ Published: March 25, 2017 \\ Copyright: Zhou et al. This is an open-access article distributed under the terms of the Creative Commons Attribution License 3.0 \\ (CC BY 3.0), which permits unrestricted use, distribution, and reproduction in any medium, provided the original author and source \\ are credited.
}

\section{ABSTRACT}

This study examined the prognostic value of the baseline red blood cell distribution width (RDW) in diffuse large B cell lymphoma (DLBCL) patients. The associations between RDW and clinical characteristics were assessed in 161 DLBCL patients from 2005 to 2016. The log-rank test, univariate analysis, and Cox regression analysis were used to evaluate the relationship between RDW and survival. A RDW of $14.1 \%$ was considered to be the optimal cut-off value for predicting prognosis. A high RDW was associated with more frequent $B$ symptoms $(P=0.001)$, a higher International Prognostic Index score $(P=0.032)$, more extranodal sites of disease $(P=0.035)$, and significantly lower Eastern Cooperative Oncology Group performance status $(P=0.031)$. The log-rank test demonstrated that patients with a high RDW had a shorter overall survival (OS) (2-year OS rate, $53.6 \%$ vs. $83.6 \%, P<0.001$ ) and progression-free survival (PFS) (2-year PFS rate, $44.7 \%$ vs. $81.8 \%, P<0.001$ ). The multivariate analysis demonstrated that RDW $\geq \mathbf{1 4 . 1} \%$ was an independent predictor of OS (odds ratio [OR] $=0.345, P<0.001)$ and PFS $(O R=0.393, P=0.001)$. We demonstrated that a high RDW predicted an unfavorable prognosis in patients with DLBCL.

\section{INTRODUCTION}

Diffuse large B-cell lymphoma (DLBCL) is the most common form of lymphoma, accounting for $25-30 \%$ of all newly diagnosed cases of adult non-Hodgkin lymphoma (NHL). DLBCL is classified as a heterogeneous entity, encompassing several morphological variants, various biological abnormalities, and variable clinical behaviors and responses to treatment [1]. The International Prognostic Index (IPI), and its variants designed for younger or elderly (e.g., age-adjusted IPI) patients and patients treated with rituximab (e.g., revised R-IPI), are the only widely accepted, validated clinical prognostic indices for DLBCL [2, 3]; however, some patients with a favorable IPI fail treatment and vice versa.

Some prognostically significant molecular and immunohistochemical characteristics of DLBCL have been identified, but cost and technical constraints make their routine application impractical; therefore, finding inexpensive, readily available surrogate prognostic markers could make an important contribution to improved risk assessment for individual patients.

Inflammatory cells and soluble mediators, such as cytokines and chemokines, are essential factors that sustain cell growth and invasion, induce angiogenesis, and suppress antitumor immune functions $[4,5]$. The presence of systemic inflammation was identified as an independent predictor of the response to treatment, overall survival (OS) and event-free survival in DLBCL patients [6].

The red blood cell distribution width (RDW) is a coefficient of the volume variation of circulating erythrocytes, and is routinely measured in clinical practice as part of a complete blood count (CBC). As an easy-tomeasure marker of the systemic inflammatory response, 
the RDW has been reported in many pathophysiological conditions, including cardiovascular disease and generally increased progressive inflammation [7-11]. The RDW is being increasingly recognized as having an important role in tumor progression and prognosis [12-17].

Here, we present our single-institution experience assessing the prognostic value of the RDW in DLBCL at diagnosis. We retrospectively analyzed a cohort of patients with DLBCL, treated from 2005 to 2016 at our institution, to investigate the prognostic role of RDW at diagnosis in our population in terms of progression-free survival (PFS) and overall survival (OS).

\section{RESULTS}

\section{Patient characteristics}

The analysis included 161 patients [median age $=59$ years (range: $18-80$ years); 91 (56.5\%) males]. The median follow-up time was 42 months (range: 6-120 months).

Based on a receiver operating curve (ROC) analysis of RDW, the patients were divided into low- and highRDW groups using a value of $14.1 \%$. The area under the curve (AUC) for RDW was 0.716 (95\% confidence interval
$[C I]=0.578-0.854)$, and the optimal cutoff value was $14.1 \%$, with $78.6 \%$ sensitivity and $64.0 \%$ specificity $(P=0.007$; Figure $1)$. There were 111 patients with a low RDW $(<14.1 \%)$ and 50 patients with a high $\operatorname{RDW}(\geq 14.1 \%)$. The patients with a high RDW more frequently showed B symptoms $(P=0.001)$ and had a higher IPI $(P=0.032)$, more extranodal sites of disease $(P=0.035)$, and significantly lower Eastern Cooperative Oncology Group performance status (ECOG-PS) $(P=0.031)$. There were no significant correlations between RDW and numerous clinical pathological factors, including age, gender, lactate dehydrogenase (LDH) at diagnosis, disease stage, pathology type, and bone marrow infiltration (Table 1).

\section{Association between RDW level and clinical outcome}

With a median follow-up of 24 months (range: 6-120 months), patients with a high RDW had a significantly lower PFS than those with a low RDW (2-year PFS, 44.7\% vs. $81.8 \%$, respectively; $P=0.000$ ) (Figure 2). The OS showed a similar tendency between the two groups (2-year OS, 53.6\% vs. 83.6\%, $P=0.000$ ) (Figure 2).

Tables 2 and 3 summarize the results of univariate and multivariate analyses of factors influencing OS and

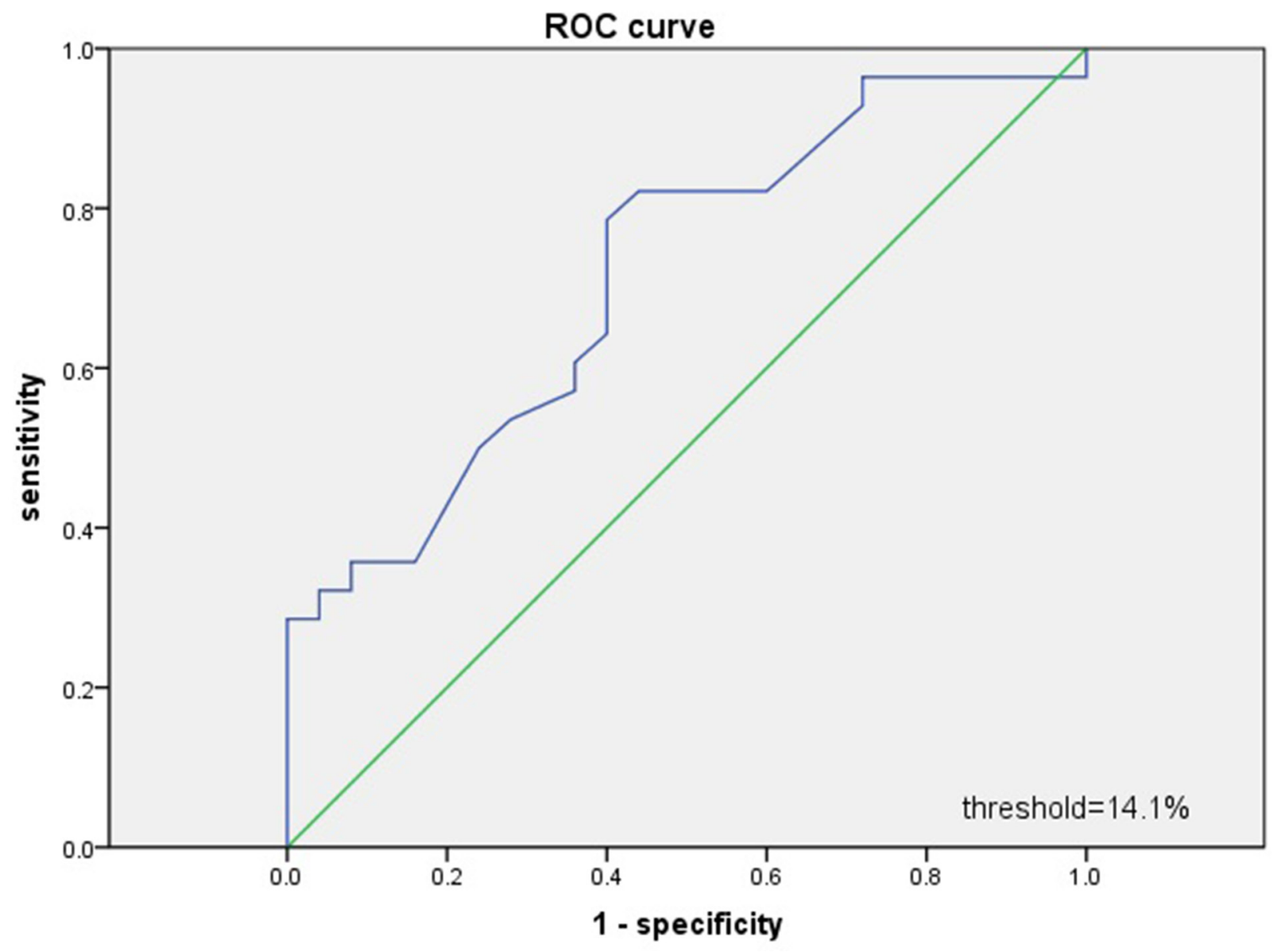

Figure 1: Receiver operating characteristic (ROC) curves analysis for RDW. 
Table 1: Clinical characteristics of DLBCL patients.

\begin{tabular}{|c|c|c|c|c|}
\hline Characteristics & Total $(n=161)$ & RDW $<14.1(n=111)$ & $R D W \geq 14.1(n=50)$ & P Value \\
\hline \multicolumn{5}{|l|}{ Gender } \\
\hline Male, n (\%) & $91(56.5 \%)$ & $63(56.8 \%)$ & $26(52.0 \%)$ & 0.610 \\
\hline Age & $59.1 \pm 11.4$ & $58.4 \pm 11.0$ & $60.8 \pm 12.4$ & 0.206 \\
\hline Ann Arbor stage, n (\%) & & & & 0.150 \\
\hline I & $49(30.4 \%)$ & $30(27.0 \%)$ & $19(38.0 \%)$ & \\
\hline II & $17(10.6 \%)$ & $10(9.0 \%)$ & $7(14.0 \%)$ & \\
\hline III & $56(34.8 \%)$ & $39(35.1 \%)$ & $17(34.0 \%)$ & \\
\hline IV & $39(24.2 \%)$ & $32(28.8 \%)$ & $7(14.0 \%)$ & \\
\hline B symptoms, n (\%) & & & & 0.001 \\
\hline Yes & $27(16.8 \%)$ & $11(9.9 \%)$ & $16(32.0 \%)$ & \\
\hline No & $134(83.2 \%)$ & $100(90.1 \%)$ & $34(68.0 \%)$ & \\
\hline ECOG PS, n (\%) & & & & 0.031 \\
\hline$<2$ & $129(80.1 \%)$ & $94(84.6 \%)$ & $35(70.0 \%)$ & \\
\hline$\geq 2$ & $32(19.9 \%)$ & $17(15.4 \%)$ & $15(30.0 \%)$ & \\
\hline $\begin{array}{l}\text { Extranodal sites of disease, } \\
\mathrm{n}(\%)\end{array}$ & & & & 0.035 \\
\hline$>1$ & $32(19.9 \%)$ & $17(\%)$ & $15(30.0 \%)$ & \\
\hline$\leq 1$ & $129(80.1 \%)$ & $94(\%)$ & $35(70.0 \%)$ & \\
\hline IPI, n (\%) & & & & 0.032 \\
\hline 0 & $33(20.5 \%)$ & $26(23.4 \%)$ & $7(14.0 \%)$ & \\
\hline 1 & $60(37.3 \%)$ & $43(38.7 \%)$ & $17(34.0 \%)$ & \\
\hline 2 & $32(19.9 \%)$ & $24(21.6 \%)$ & $8(16.0 \%)$ & \\
\hline 3 & $23(14.3 \%)$ & $10(9.0 \%)$ & $13(26.0 \%)$ & \\
\hline 4 & $10(6.2 \%)$ & $5(4.5 \%)$ & $5(10.0 \%)$ & \\
\hline 5 & $3(1.9 \%)$ & $3(2.7 \%)$ & $0(0 \%)$ & \\
\hline LDH, n (\%) & & & & 0.082 \\
\hline$\leq 1 \times \mathrm{ULN}$ & $100(62.1 \%)$ & $74(66.7 \%)$ & $26(52.0 \%)$ & \\
\hline$>1 \times \mathrm{ULN}$ & $61(37.9 \%)$ & $37(33.3 \%)$ & $24(48.0 \%)$ & \\
\hline $\begin{array}{l}\text { Bone marrow involvement, } \\
\mathrm{n}(\%)\end{array}$ & & & & 0.287 \\
\hline YES & $10(6.2 \%)$ & $5(4.5 \%)$ & $5(10.0 \%)$ & \\
\hline NO & $151(93.8 \%)$ & $106(95.5 \%)$ & $45(90.0 \%)$ & \\
\hline Pathology type & & & & 0.843 \\
\hline GCB subtype & $39(24.2 \%)$ & $26(23.4 \%)$ & $13(26 \%)$ & \\
\hline Non-GCB subtype & $122(75.8 \%)$ & $85(76.6 \%)$ & $37(74 \%)$ & \\
\hline $\operatorname{Hemoglobin}(\mathrm{g} / \mathrm{L})$, mean \pm SD & $122.9 \pm 19.0$ & $127.8 \pm 16.7$ & $112.1 \pm 19.4$ & $<0.001$ \\
\hline $\mathrm{RDW}$, mean $\pm \mathrm{SD}$ & $13.6 \pm 1.3$ & $13.0 \pm 0.7$ & $15.0 \pm 1.2$ & $<0.001$ \\
\hline
\end{tabular}

Abbreviations: ECOG, Eastern Cooperative Oncology Group; IPI, International Prognostic Index; LDH, lactate dehydrogenase; PS, performance status; GCB, germinal center B cell; RDW, red blood cell distribution width. 
PFS in patients with DLBCL. Univariate Cox regression analysis showed that predictors of OS were a high ECOGPS ( $\geq 2, P=0.003)$ and high clinical stage (stages III and IV, $P=0.016)$, with $\mathrm{B}$ symptoms $(P=0.002)$, high IPI $(>2, P<0.001)$, elevated RDW level $(P<0.001)$, elevated LDH $(P=0.003)$, more extranodal sites of disease $(>1$, $P=0.001)$, low hemoglobin $(P<0.001)$ and bone marrow involvement $(P=0.026)$. Independent predictors of PFS were a high ECOG-PS $(\geq 2, P=0.008)$, high clinical stage (stages III and IV, $P=0.024$ ) with $B$ symptoms ( $P=0.001)$, high IPI $(>2, P<0.001)$, elevated RDW level $(P<0.001)$, more extranodal sites of disease $(>1$, $P=0.0003)$ with bone marrow involvement $(P=0.049)$, low hemoglobin $(P<0.001)$ and elevated LDH $(P=0.001)$ (Table 2)

Multivariate analysis, which included all of the parameters significant at $P<0.05$ in the univariate analyses, revealed that $\mathrm{RDW} \geq 14.1 \%$ was the only independent predictor of OS (odds ratio $[\mathrm{OR}]=3.062,95 \% \mathrm{CI}=1.669$ $5.619, P<0.001)$ and $\mathrm{PFS}(\mathrm{OR}=2.650,95 \% \mathrm{CI}=1.448$ 4.849, $P=0.002$ ) (Table 3).

\section{DISCUSSION}

The RDW value, obtained at diagnosis as part of a standard automated $\mathrm{CBC}$, is a novel, immediate prognosticator in DLBCL patients. Our results for DLBCL confirm reports by other investigators [12]; we provide evidence that a high RDW at diagnosis is strongly

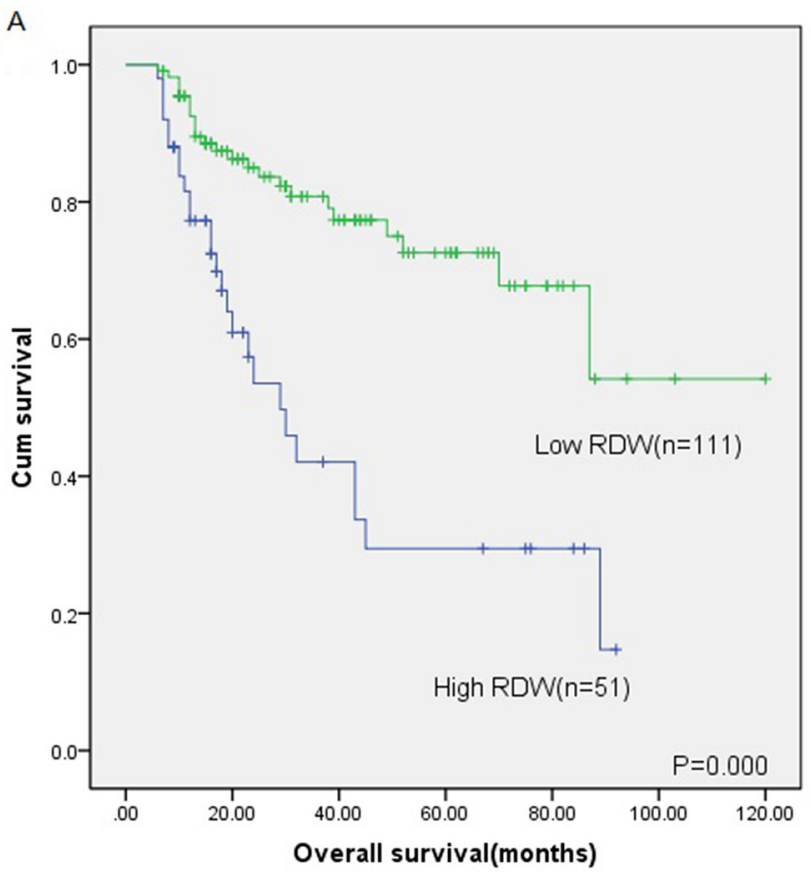

associated with high-risk clinical features in patients who receive rituximab-based chemotherapy.

RDW is an automated measure of the heterogeneity of red blood cell dimensions (e.g., anisocytosis) and is performed routinely as part of a CBC. Traditionally, it has played a role in the differential diagnosis of anemia [18]. Recently, RDW is increasingly being recognized to play important roles in carcinogenesis and tumor progression $[12,13,16,17]$. There is evidence of its prognostic value in various malignancies [15, 19-22]. Some studies and a meta-analysis demonstrated that RDW is a potent predictor of all-cause mortality, including cancer-related deaths [23-25]. In patients with symptomatic multiple myeloma, elevated RDW values were associated with a higher disease stage according to the International Staging System, and a poor prognosis [26]. RDW is reported to be a useful biomarker for distinguishing between benign and malignant breast tumors. An elevated pretreatment RDW may be associated with a worse prognosis in young women with breast cancer [27]. Moreover, RDW elevation is significantly correlated with larger primary tumors, more infiltrated axillary lymph nodes, and advanced stages [15].

The mechanism underlying the relationship between RDW and survival or disease activity is not clear. Research has found an association between RDW and a variety of inflammatory markers, such as high-sensitivity C-reactive protein, the erythrocyte sedimentation rate, interleukin-6, soluble transferrin receptor, and soluble tumor necrosis factor receptors I and II [9]. A high RDW reflects underlying inflammation that impairs erythrocyte

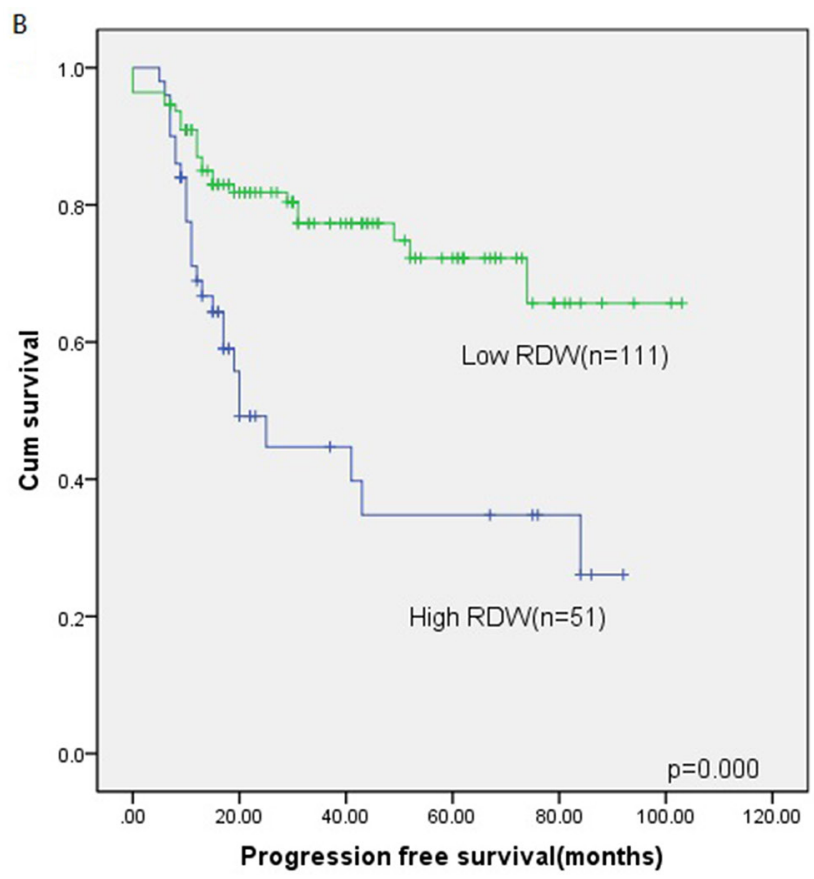

Figure 2: Kaplan-Meier survival analysis of RDW. Overall survival (A) and progression-free survival (B) according to RDW in DLBCL patients. 
Table 2: Univariate analysis of clinical factors for PFS and OS in 161 patients.

\begin{tabular}{|c|c|c|c|c|c|c|}
\hline Characteristics & & OS & & & PFS & \\
\hline & OR & $95 \% \mathrm{CI}$ & P value & OR & $95 \% \mathrm{CI}$ & Pvalue \\
\hline $\operatorname{Age}(\geq 60)$ & 1.242 & $0.711-2.169$ & 0.446 & 1.243 & $0.720-2.147$ & 0.435 \\
\hline Gender & 1.016 & $0.580-1.779$ & 0.956 & 1.020 & $0.589-1.764$ & 0.944 \\
\hline B symptoms & 2.564 & $1.414-4.649$ & 0.002 & 2.731 & $1.510-4.941$ & 0.001 \\
\hline $\operatorname{ECOG} \operatorname{PS}(\geq 2)$ & 2.525 & $1.369-4.655$ & 0.003 & 2.281 & $1.244-4.184$ & 0.008 \\
\hline $\mathrm{LDH}(>\mathrm{ULN})$ & 2.333 & $1.334-4.082$ & 0.003 & 2.529 & $1.454-4.396$ & 0.001 \\
\hline Stage (III and IV) & 1.994 & $1.136-3.501$ & 0.016 & 1.894 & $1.089-3.293$ & 0.024 \\
\hline Bone marrow involvement & 2.656 & $1.125-6.273$ & 0.026 & 0.423 & $0.180-0.997$ & 0.049 \\
\hline $\operatorname{IPI}(>2)$ & 3.105 & $1.734-5.559$ & $<0.001$ & 2.901 & $1.633-5.154$ & $<0.001$ \\
\hline $\mathrm{RDW} \geq 14.1$ & 3.310 & $1.890-5.795$ & $<0.001$ & 2.947 & $1.691-5.137$ & $<0.001$ \\
\hline $\begin{array}{l}\text { Extranodal sites of } \\
\text { disease }(>1)\end{array}$ & 2.724 & $1.487-4.991$ & 0.001 & 2.454 & $1.350-4.458$ & 0.003 \\
\hline Pathology type & 1.078 & $0.537-2.166$ & 0.833 & 1.193 & $0.597-2.383$ & 0.618 \\
\hline Hemoglobin & 0.973 & $0.958-0.988$ & $<0.001$ & 0.972 & $0.958-0.987$ & $<0.001$ \\
\hline
\end{tabular}

Abbreviations: ECOG, Eastern Cooperative Oncology Group; PS, performance status; LDH, lactate dehydrogenase; IPI, International Prognostic Index; RDW, red blood cell distribution width.

Table 3: Multivariate analysis of clinical factors for PFS and OS.

\begin{tabular}{|c|c|c|c|c|c|c|}
\hline \multirow[t]{2}{*}{ Characteristics } & \multicolumn{3}{|c|}{ OS } & \multicolumn{3}{|c|}{ PFS } \\
\hline & OR & $95 \% \mathrm{CI}$ & Pvalue & OR & $95 \% \mathrm{CI}$ & P value \\
\hline B symptoms & 1.484 & $0.640-3.444$ & 0.358 & 1.658 & $0.733-3.753$ & 0.225 \\
\hline $\operatorname{IPI}(>2)$ & 1.057 & $0.389-2.874$ & 0.913 & 0.974 & $0.370-2.561$ & 0.957 \\
\hline $\operatorname{ECOG} \operatorname{PS}(\geq 2)$ & 1.359 & $0.647-2.855$ & 0.417 & 1.181 & $0.583-2.393$ & 0.644 \\
\hline $\mathrm{LDH}(>\mathrm{ULN})$ & 1.721 & $0.760-3.898$ & 0.193 & 2.061 & $0.929-4.573$ & 0.075 \\
\hline Stage (III and IV) & 0.645 & $0.257-1.616$ & 0.349 & 0.643 & $0.265-1.559$ & 0.328 \\
\hline Bone marrow involvement & 1.145 & $0.403-3.251$ & 0.799 & 1.211 & $0.434-3.377$ & 0.715 \\
\hline $\begin{array}{l}\text { Extranodal sites of } \\
\text { disease }(>1)\end{array}$ & 2.561 & $1.030-6.370$ & 0.053 & 2.299 & $0.950-5.565$ & 0.065 \\
\hline $\mathrm{RDW} \geq 14.1$ & 3.062 & $1.669-5.619$ & $<0.001$ & 2.650 & $1.448-4.849$ & 0.002 \\
\hline Hemoglobin & 0.984 & $0.964-1.004$ & 0.108 & 0.985 & $0.966-1.004$ & 0.113 \\
\hline
\end{tabular}

Abbreviations: ECOG, Eastern Cooperative Oncology Group; PS, performance status; LDH, lactate dehydrogenase; IPI, International Prognostic Index; RDW, red blood cell distribution width.

maturation and leads to inadequate production of the hormone erythropoietin, undernutrition (i.e., deficiencies in nutrients such as iron, vitamin $\mathrm{B}_{12}$, and folate), oxidative damage, and age-associated diseases via changes in erythropoiesis [28]. Inflammation impairs erythropoiesis and contributes to the increase in RDW. Furthermore, inflammation can cause changes in red blood cell maturation by altering the red cell membrane, leading to increased RDW [29]. It is also associated with impaired iron release from reticuloendothelial macrophages, which can be observed in anemia caused by inflammatory conditions [30].

The role of inflammation in the development of lymphoma has long been recognized and investigated extensively. DLBCL development and invasion depend on multiple interactions between tumor cells and nonneoplastic cells, and on their interaction with the surrounding stroma/matrix environment [31]. In this 
study, we found a positive association between RDW and B symptoms, a higher IPI, and a lower ECOG- PS. This might also reflect an association between RDW and the increased inflammation or malnutrition caused by cancer progression.

This study was limited in that it was conducted at a single center and included a retrospective analysis of a small number of patients. Further multicenter, prospective studies containing more patients are needed. Despite these limitations, our study suggested that pretreatment RDW is associated with PFS and OS in DLBCL patients treated with rituximab and $\mathrm{CHOP}$ (cyclophosphamide, doxorubicin, vincristine, prednisone; R-CHOP) or similar chemotherapy. A high RDW before treatment initiation was an predictor of unfavorable prognosis in DLBCL patients. Based on our findings, we recommend that RDW be used as an easily determined, inexpensive biomarker for risk assessment in patients with DLBCL.

\section{MATERIALS AND METHODS}

\section{Patients and methods}

The inclusion criteria were a diagnosis of de novo DLBCL, treatment with R-CHOP or R-CHOP-like chemotherapy (e.g., EPOCH and CHOEP regimens, used when patients are young, with an elevated LDH and bulky mass, and are of Stage III/ IV; no patients received radiotherapy) for at least four cycles, complete clinical data, and followed at the First Affiliated Hospital of Wenzhou Medical University from 2005 to 2016. The dose of rituximab was $375 \mathrm{mg} / \mathrm{m}^{2}$ for all patients. We excluded patients with primary central nervous system lymphoma, transformed NHL, or human immunodeficiency virusassociated DLBCL, and those who were lost to follow-up. Patients with inflammatory conditions, including infections or collagen diseases, anemia, and other diseases of the hematological system, cardiovascular and cerebrovascular disorders, a previous malignancy, pre-treatment with induction chemotherapy or radiotherapy, or non-cancerassociated death, were excluded. From June 2005 until February 2016, 161 patients with DLBCL qualified for the study, which was approved by the Institutional Review Board of the First Affiliated Hospital of Wenzhou Medical University and was performed in accordance with the principles of the Declaration of Helsinki.

The RDW was calculated in routine blood tests performed immediately after DLBCL was diagnosed and before initiating any treatment (pretreatment RDW). Receiver operating characteristic (ROC) curve analysis was used to determine the optimal RDW cutoff. The binary clinical outcome (death/survival) was determined 2 years after diagnosis. Patients were categorized as "alive/censored" when the follow-up time was longer than 2 years, and as "dead" when they died before this time.
The following demographic characteristics, clinical features, and laboratory parameters were obtained from medical records: sex, age, disease stage, IPI, presence of B symptoms, LDH, hemoglobin ( $\mathrm{Hb})$, pathology type, ECOG-PS, and number of extranodal locations involved.

The response and relapse criteria were as defined by Cheson et al. [32]. OS was defined as the time from diagnosis to death. PFS was defined as the time from diagnosis to relapse.

\section{Statistical analysis}

The statistical analyses were performed using SPSS software (ver. 17.0). Correlations between RDW and clinical parameters were evaluated using the chi-square or Fisher's exact test. OS and PFS were analyzed using Kaplan-Meier curves, which were compared using the logrank test. Categorical variables were compared using the chi-square test. Variables that were significant at $P<0.05$ in the univariate Cox regression analysis were included in the multivariate analysis using forward stepwise selection. $P<0.05$ was considered statistically significant and all $P$-values were two-tailed.

\section{ACKNOWLEDGMENTS}

This work was supported by the National Natural Science Foundation of China (No. 81502793), Zhejiang Provincial Natural Science Foundation (No. LY16H080006) and the Public Welfare Science and Technology Project of Wenzhou (Nos.Y20150034).

\section{CONFLICTS OF INTEREST}

The authors have no funding or conflicts of interest to disclose.

\section{REFERENCES}

1. Habermann TM. New developments in the management of diffuse large B-cell lymphoma. Hematology. 2012; 17 Suppl 1:S93-97.

2. The International Non-Hodgkin's Lymphoma Prognostic Factors Project. A predictive model for aggressive nonHodgkin's lymphoma. N Engl J Med. 1993; 329:987-994.

3. Sehn LH, Berry B, Chhanabhai M, Fitzgerald C, Gill K, Hoskins P, Klasa R, Savage KJ, Shenkier T, Sutherland J, Gascoyne RD, Connors JM. The revised International Prognostic Index (R-IPI) is a better predictor of outcome than the standard IPI for patients with diffuse large B-cell lymphoma treated with R-CHOP. Blood. 2007; 109:1857-1861.

4. Mantovani A, Allavena P, Sica A, Balkwill F. Cancerrelated inflammation. Nature. 2008; 454:436-444. 
5. Hanahan D, Weinberg RA. Hallmarks of cancer: the next generation. Cell. 2011; 144:646-674.

6. Perisa V, Zibar L, Knezovic A, Perisa I, Sincic-Petricevic J, Aurer I. Prognostic nutritional index as a predictor of prognosis in patients with diffuse large B cell lymphoma. Wien Klin Wochenschr. 2016 Sep 8. [Epub ahead of print].

7. Forhecz Z, Gombos T, Borgulya G, Pozsonyi Z, Prohaszka Z, Janoskuti L. Red cell distribution width in heart failure: prediction of clinical events and relationship with markers of ineffective erythropoiesis, inflammation, renal function, and nutritional state. Am Heart J. 2009; 158:659-666.

8. Yesil A, Senates E, Bayoglu IV, Erdem ED, Demirtunc R, Kurdas Ovunc AO. Red cell distribution width: a novel marker of activity in inflammatory bowel disease. Gut Liver. 2011; 5:460-467.

9. Lippi G, Targher G, Montagnana M, Salvagno GL, Zoppini G, Guidi GC. Relation between red blood cell distribution width and inflammatory biomarkers in a large cohort of unselected outpatients. Arch Pathol Lab Med. 2009; 133:628-632.

10. Jo YH, Kim K, Lee JH, Kang C, Kim T, Park HM, Kang $\mathrm{KW}$, Kim J, Rhee JE. Red cell distribution width is a prognostic factor in severe sepsis and septic shock. Am J Emerg Med. 2013; 31:545-548.

11. Grant BJ, Kudalkar DP, Muti P, McCann SE, Trevisan M, Freudenheim JL, Schunemann HJ. Relation between lung function and RBC distribution width in a populationbased study. Chest. 2003; 124:494-500.

12. Perisa V, Zibar L, Sincic-Petricevic J, Knezovic A, Perisa I, Barbic J. Red blood cell distribution width as a simple negative prognostic factor in patients with diffuse large B-cell lymphoma: a retrospective study. Croat Med J. 2015; 56:334-343.

13. Koma Y, Onishi A, Matsuoka H, Oda N, Yokota N, Matsumoto Y, Koyama M, Okada N, Nakashima N, Masuya D, Yoshimatsu H, Suzuki Y. Increased red blood cell distribution width associates with cancer stage and prognosis in patients with lung cancer. PLoS One. 2013; 8:e80240.

14. Ay S, Eryilmaz MA, Aksoy N, Okus A, Unlu Y, Sevinc B. Is early detection of colon cancer possible with red blood cell distribution width? Asian Pac J Cancer Prev. 2015; 16:753-756.

15. Seretis C, Seretis F, Lagoudianakis E, Gemenetzis $\mathrm{G}$, Salemis NS. Is red cell distribution width a novel biomarker of breast cancer activity? Data from a pilot study. J Clin Med Res. 2013; 5:121-126.

16. Riedl J, Posch F, Konigsbrugge O, Lotsch F, Reitter EM, Eigenbauer E, Marosi C, Schwarzinger I, Zielinski C, Pabinger I, Ay C. Red cell distribution width and other red blood cell parameters in patients with cancer: association with risk of venous thromboembolism and mortality. PLoS One. 2014; 9:e111440.

17. Albayrak S, Zengin K, Tanik S, Bakirtas H, Imamoglu A, Gurdal M. Red cell distribution width as a predictor of prostate cancer progression. Asian Pac J Cancer Prev. 2014; 15:7781-7784.

18. Weiss G, Goodnough LT. Anemia of chronic disease. N Engl J Med. 2005; 352:1011-1023.

19. Beyazit Y, Kekilli M, Ibis M, Kurt M, Sayilir A, Onal IK, Purnak T, Oztas E, Tas A, Yesil Y, Arhan M. Can red cell distribution width help to discriminate benign from malignant biliary obstruction? A retrospective single center analysis. Hepatogastroenterology. 2012; 59:1469-1473.

20. Baicus C, Caraiola S, Rimbas M, Patrascu R, Baicus A, for Grupul de Studiu al Scaderii Ponderale I. Utility of routine hematological and inflammation parameters for the diagnosis of cancer in involuntary weight loss. J Investig Med. 2011; 59:951-955.

21. Ozkalemkas F, Ali R, Ozkocaman V, Ozcelik T, Ozan U, Ozturk H, Kurt E, Evrensel T, Yerci O, Tunali A. The bone marrow aspirate and biopsy in the diagnosis of unsuspected nonhematologic malignancy: a clinical study of 19 cases. BMC Cancer. 2005; 5:144.

22. Spell DW, Jones DV Jr, Harper WF, David Bessman J. The value of a complete blood count in predicting cancer of the colon. Cancer Detect Prev. 2004; 28:37-42.

23. Perlstein TS, Weuve J, Pfeffer MA, Beckman JA. Red blood cell distribution width and mortality risk in a community-based prospective cohort. Arch Intern Med. 2009; 169:588-594.

24. Patel KV, Ferrucci L, Ershler WB, Longo DL, Guralnik JM. Red blood cell distribution width and the risk of death in middle-aged and older adults. Arch Intern Med. 2009; 169:515-523.

25. Hu L, Li M, Ding Y, Pu L, Liu J, Xie J, Cabanero M, Li J, Xiang R, Xiong S. Prognostic value of RDW in cancers: a systematic review and meta-analysis. Oncotarget. 2016; 8:16027-16035. doi: 10.18632/oncotarget.13784.

26. Lee H, Kong SY, Sohn JY, Shim H, Youn HS, Lee S, Kim HJ, Eom HS. Elevated red blood cell distribution width as a simple prognostic factor in patients with symptomatic multiple myeloma. Biomed Res Int. 2014; 2014:145619.

27. Huang DP, Ma RM, Xiang YQ. Utility of Red Cell Distribution Width as a Prognostic Factor in Young Breast Cancer Patients. Medicine (Baltimore). 2016; 95: 3430.

28. Evans TC, Jehle D. The red blood cell distribution width. J Emerg Med. 1991; 9 Suppl 1:71-74.

29. Demirkol S, Balta S, Cakar M, Unlu M, Arslan Z, Kucuk U. Red cell distribution width: a novel inflammatory marker in clinical practice. Cardiol J. 2013; 20:209. 
30. Sharma S, Nemeth E, Chen YH, Goodnough J, Huston A, Roodman GD, Ganz T, Lichtenstein A. Involvement of hepcidin in the anemia of multiple myeloma. Clin Cancer Res. 2008; 14:3262-3267.

31. Mbeunkui F, Johann DJ Jr. Cancer and the tumor microenvironment: a review of an essential relationship. Cancer Chemother Pharmacol. 2009; 63:571-582.
32. Cheson BD, Horning SJ, Coiffier B, Shipp MA, Fisher RI, Connors JM, Lister TA, Vose J, Grillo-Lopez A, Hagenbeek A, Cabanillas F, Klippensten D, Hiddemann $\mathrm{W}$, et al. Report of an international workshop to standardize response criteria for non-Hodgkin's lymphomas. NCI Sponsored International Working Group. J Clin Oncol. 1999; 17:1244. 